\title{
Feijoo en México
}

\section{Notas de asedio}

\author{
por Salvador CRUZ \\ Miembro Correspondiento del Seminario de Cultura Mexieana \\ Tehuacán (México)
}

Partamos de un principio cierto y preciso: el Teatro Crítico Universal, compuesto por su autor "para desengaño de errores comunes", fue una obra que de inmediato cumplió su destino, fue una obra de sensación y actualidad. De septiembre de 1726 al mes de abril de 1728 en que aparecen los dos primeros tomos, se abre el fuego de varias polémicas con un saldo de, más o menos, setenta impresos y manuscritos. ${ }^{1} \mathrm{Si}$ muchos aplaudían, no eran menos los que denostaban. Entre los que desde temprana hora fueron afectos al autor, estuvo un mexicano, José Antonio de Legaria, natural de la villa de Atlixco en el obispado de la Puebla de los Angeles. En 1730 dio a luz en Madrid una curiosa Congratulación al P. M. D. Benito Feijoo por sus panegíricos Discursos; y nuevas pruebas que apoyan su Mapa Intelectual o Discurso 15 del Tomo $2 .^{2}$

1. Millares Carlo, Agustín: Preliminares en Feijoo, Teatro Critico Universal, Clásicos Castellanos de la Lectura, Madrid, 1923.

2. Beristáin y Souza, Mariano: Biblinteca Hispanoamericana Septentrional, 2.a ed., Amecameca, 1883, t. II, art. "Legarias. 
El 8 de marzo de 1734, otro novohispano, don Mariano Gregorio de Elizalde Ita y Parra, tuvo la oportunidad de rendir en Madrid el Parecer para el tomo sexto del Teatro. Quien había sido Rector de la Real Universidad de México es idóneo al reconocer en la obra de Feijoo su «común utilidad» y señalar que se gozaba de su lectura hasta en las Filipi. nas y Asia. ${ }^{3}$

Doce años después, en 1746, el Dr. Andrés de Arce y Miranda noticiaba al ilustre Eguiara sobre los escritores de Nueva España, pero insistiendo en dos puntos feijonianos: desterrar la superchería de que los criollos, así como son precoces, pronto llegan a la decrepitud, y preferir la denominación de españoles americanos para los criollos. ${ }^{4}$ Arce y Miranda, reconocido estudioso de su tiempo, era natural de Huejotzingo, también del obispado de la Puebla de los Angeles.

Por fin, en 1755 aparece el primer tomo de la Bibliot/2eca Mexicana de Eguiara, punto inicial de la bibliografía en Nueva España. En los prolegómenos del libro, en los Anteloquia XII y XIII, el maestro de Oviedo se hace oír:

aXII. En que se examina con cuidado la precocidad de Ios ingenios americanos y se corrobora la opinión expresada acerca de este asunto por el eruditísimo y muy autorizado crítico fray Benito Feijoo.

"XIII. En que se prueba ser pura ficción la rapidez con que los americanos decaen del uso de sus facultades intelectuales; y se relega tal creencia al mundo de las fábulas..n5

Pero no sólo se discutía a Feijoo en la Nueva España dieciochesca. Para 1759 alcanza el honor de una edición mexicana, cuando la nueva imprenta del Colegio Real y más antiguo de San Ildefonso republica unos pliegos que ya corrían impresos en España bajo la paternidad de don Gerónymo Montenegro y en el colofón las iniciales F. B. G. F. M. Son el romance Desengaño de un pecador y las Décimas a la conciencia, en metáfora de relox. La reimpresión estaba dedicada «a su verdaderc autor, el padre Feijoo» ${ }^{6}$ Sólo queremos adelantar la idea de que en la edición pudiera haber intervenido Clavijero, Prefecto de estudios en

\footnotetext{
3. Teatro, VI, primerat edicion, Madrid, 1734.

4. Medina, José Toribio: La Lmprenta en México, Santiago de Clible, 1907, t. I, ps. CCXXXVIl. CCXXXVIII. 5. Eguiara y Eguren, Juan José de: Prólogos a la Bibliotheci Mexicana Versión española anotada por
Agustín Millares Carlo, México, 1944 .

6. Millares Carlo. Agustín: Introducción a Feijoo, Dos Discursos sobre América, Biblioteca Enci-
pedica Popular, México, 1945.
} 
San Ildefonso, que en 1759 investigaba en los archivos jesuitas de México.

Dedicada «a las Universidades de España y de América», en 1760 imprimió en México don Francisco Ignacio Cigala una Carta Segunda dirigida a Feijoo, para impugnarle el discurso Peso del aire. ${ }^{8}$ Cigala, que ne creía en otras verdades que las aristotélicas, era natural de La Habana y a la sazón arrendatario del trapiche de San Joseph Tilapa en el valle de Tehuacán, también perteneciente al obispado de la Puebla.

Pero a Feijoo se le leía en el Nuevo y el Viejo Mundo. Expulsos los jesuitas en 1767, el más importante núcleo mexicano se radicó en Bolonia. Y ahí un grupo lo leyó hasta beberle el alma: Clavijero, Castro, Landívar. Precisamente en 1782 publica Landívar la edición definitiva de su Rusticatio Mexicana, y la presencia del autor del Teatro Crítico se revela en una mención poética, "el famoso Cola», que es el mismísimo Peze Cola o Nicolao de Feijoo. ${ }^{10}$

Cierra la fama dieciochesca un hecho en que se asocia el nombre de México. En 1789 don Juan de Escoiquiz publica en Madrid su poema heroico México Conquistada. Y en el prólogo de la obra el canónigo de Zaragoza, el Sumiller de Cortina de Su Majestad y Maestro de Geografía y Matemáticas del Serenísimo Príncipe de Asturias, glosa con emociór. una enseñanza feijoniana comúnmente olvidada: la distinción entre el amor a la patria y la pasión nacional."

De una manera clara y precisa, la influencia de Feijoo es perceptible en los renovadores de la ciencia en México: Alzate y Bartolache. Aquél prolonga sus simpatías y se adhiere a la Medicina Scéptica del doctor Martín Martínez; Bartolache declara que venera a Feijoo y ha gustado de todos sus libros. ${ }^{12}$

7. Burrus, Ernest J.: Clavigero and the lost Sigüenza y Góngora Manuscripts, Sobretiro de Esludios de Cultura Nahuatl, vol. I, México, 1959.

8. Beristáin, op, cit., t. I, art. «Cigala».

9. Cruz, Salvador: «Feijoo en el valle de Tehuacán, Boletín Bibliográfico Horizontes, núm. 38, México, 1964.

10. Valdés, Octaviano: Traducción y notas a Landívar, Por los campos de México, Biblioteca del Estudiante Universitario, México, 1952.

11. Cruz, Salvador: "Nota a un fragmento de Escoiquiz, México conquistada", Revista Huytlale, núm. 29, Tapachula, Chis., 1957.

12. De la Maza, Francisco: Los exámenes universitarios del Doctor José Ignacio Bartolache en 1772 , México, Imprenta Universitaria, 1948. 
Pero, sobre todo influye, como ya lo hemos dicho, en el grupo que antevé la independencia, en el grupo de jesuitas expulsos. Los mismos que realizaron "aquel tipo superior de humanismo que casi se identifica con el más noble y pleno sentido de la palabra humanidad $» ;^{13}$ los mismos que practicaron un «liberalismo cristiano», ${ }^{14}$ que así afirmaba la libertad como desautorizaba la esclavitud..$^{15}$

La filosofía moderna en México también le debe el arranque al maestro de Oviedo: «como en España, aquí prepararon el camino Feijoo, sobre todo, Tosca y Losada $3 .{ }^{16} \mathrm{Y}$ para ejemplo bastan dos: el del renovador Juan Benito Díaz de Gamarra, que lo toma por guía en su texto de Filosofía (México, 1774), y el de Clavijero, creador de la moderna imagen histórica de México, de quien su primitivo biógrafo dice que tomó "como guías a Feijoo y a Tosca ${ }^{17}$ No se olvide que el iniciador de la independencia mexicana, Miguel Hidalgo y Costilla, fue discípulo de Clavijero y sabemos con certeza que leía a Feijoo; llegó a escribir una Disertación sobre el verdadero método de estudiar Theología Escolástica. $^{18}$

El Grito de Dolores mueve la brújula de Nueva España. Al avance de Hidalgo siguen las campañas de Morelos. En el valle de Tehuacán acampan jefes insurgentes como don Ignacio López Rayón y don Juan Nepomuceno Rossáins. Pero ambos reclaman la supremacía y las rivalidades llegan al máximo. Como son licenciados, pleitean con la pluma. Es así como, el 17 de julio de 1814, Rossáins publica en Tehuacán un papel rotulado Justa Repulsa, que lleva el mismo aliento de réplica que su necesario antecedente, la Justa Repulsa de inicuas acusaciones, que en 1749 lanzara Feijoo contra Soto-Marne. ${ }^{19}$

Bien había querido el maestro de Oviedo que su escenario crítico fuese universal. A la hora en que México pelea su independencia no falta un redoble feijoniano.

13. Méndez Plancarte, Gabriel: Humanistas del siglo XVIII, México, Biblioteca del Est. Univ., 1941.

14. Navarro, Bernabé: aLos jesuitas y la Independencia», en Abside, t. XVI, núm. 1, México, 1952.

15. Id.: "El pensamiento moderno de los Jesuitas mexicanos del siglo XVIII", en La Palabra $y$ el Hombre, núm. 29, Xalapa, Ver., 1964.

16. Id.: Sentido y función de la Filosofía moderna en México en el siglo XVIII. Memoria del Congreso Científico Mexicano, t. XV, México, 1953.

17. Maneiro, Juan Luis: Vidas de mexicanos ilustres, Biblioteca del Estudiante Univ., Méxíco, 1956.

18. Méndez Plancarte, Gabriel: Edición y nota de la Disertación en Abside, IV, núra. 9, México, 1940.

19. Vid. nota 9. 
Digámoslo a lo Américo Castro: Sin Feijoo, Lizardi no hubiera sido lo que fue..$^{20}$

En tierras de América, a la hora en que nace la novela, Lizardi alcanza el gran soplo renovador de España -Feijoo, Cadalso, Jovellanos, el P. Isla, Torres Vallarroel, Rafael Melchor de Macanaz, Francisco de Peñaranda-. El coro de inconformes mexicanos no es menos luminoso —Díaz de Gamarra, el P. Alzate, Lardizábal y Uribe, Sor Juana.

En particular, Feijoo se enfrenta a las verdades basadas en el $\mathrm{Ma}$ gister dixit. Declara, sostiene y defiende que, en cuanto a método, "el analítico es muchas veces mejor que el escolástico". Lizardi, contemporáneo suyo en el espacio, echará por el mismo camino. Su gran personaje, el Periquillo Sarniento, relata que acabó sus cursos como estudiante gramático e ingresa al Colegio de San Ildefonso. Para su fortuna, el maestro de filosofía era un renovador, un ecléctico que «escogió lo mejor de la lógica de Aristóteles y lo que le pareció más probable de los autores modernos".

Sin embargo, la intención crítica se define cuando el Periquillo comenta :

«A pesar de este prudente método, todavía aprendimos bastantes despropósitos de aquellos que se han enseñado por costumbre, y los que convenía quitar, según la razón y hace ver el ilustrísimo Feijoo en los discursos X, XI y XII, del tomo séptimo de su Teatro Crítico.»

Aquí está ya el de Oviedo, no transparentándose, sino de viva voz.

También en sus obras menores Lizardi se apoya en Feijoo. En uno de sus diálogos, la Impugnación de los gatos Barbilucio y Machucho, se lee que

«los vicios no son frutas del tiempo que se dan como las peras por junio y los chayotes por noviembre, sino defectos peculiares del hombre que los tiene o deja de tener en todos tiempos; bueno fuera que leyera ese rojo escritor [Raynal] el tratado de la senectud moral del género humano del benedictino Feijoo..."

Llega Feijoo a una conclusión muy fuera de su siglo, como de quien ve con nitidez el paisaje del tiempo: «es cosa muy ordinaria atribuir a milagros los que son efectos de la naturaleza.» $\mathrm{Y}$ en tiempos tan milagreros como eran los de la colonia en México, Lizardi se acoge a la lección. Periquillo naufraga, pero muy a tiempo se procura una tabla de salvación. No bien se ha aferrado a ella, cuando es testigo del hundimiento

20. Nos hemos permitido seleccionar varios párrafos de nuestro estudio «Feijoo y Lizardi», publicado en la revista Cuadernos, núm. 88, Paris, 1964. 
total del buque. Es el único que ha quedado con vida. Como buen mexicano, invoca a la Virgen de Guadalupe. Sabe que no es más que un juguete de las olas y los vientos. Casi a punto de perecer, amaina la tormenta y amanece. De cara al sol, parece sucumbir cuando unos pescadores lo rescatan. $\mathrm{Y}$, al volver en sí, está a salvo rodeado de curiosos...

Como fruto a punto de caer, el lector presiente la palabra milagro. Pero el espíritu feijoniano se ha abierto paso entre el movimiento de la acción. Sencillamente, Periquillo debe seguir viviendo para cumplir la lección de su vida («fue pecador en vida y murió santo»). Lo milagroso no aparece por ninguna parte.

A la consumación de la independencia mexicana siguen años aciagos, hasta que lenta, quizá demasiado lentamente, se asegura la República. $Y$ no es posible que en medio del caos prosperen los afanes literarios. Así es como se abre una gran laguna que, sin duda, irán llenando futuras investigaciones.

En 1891 un curioso publicista de la provincia mexicana, el Dr. Agustín Rivera, reimprimió en Lagos de Moreno, Jalisco, el discurso VIII del tomo VII del Teatro, El toro de San Marcos, la bestia adorada de Extremadura. Años después, en 1909 y en Mazatlán, Sinaloa publicó el discurso VI del tomo III, con el título de San Ganelón o Milagros supuestos. ${ }^{21}$

Modernamente ha cobrado vigencia el discurso sobre los españoles americanos. Recordamos así el estudio que en 1942 publicó en la Revista Iberoamericana el investigador Hermenegildo Corbató, ${ }^{22}$ en donde, por cierto, no hace mención de los Anteloquia de Eguiara ni, por lo tanto, del eco de Feijoo. ${ }^{23}$ Por fortuna, dos años después, en 1944, se publicó la traducción de ellos, con lo que el tema se redondeó felizmente. ${ }^{24}$

\footnotetext{
21. Vid. nota 6 .

22. Corbató, Hermenegildo: «Feijoo y los españoles americanos», sobretiro de la Revista Iberoamericana, México, 1942 (mayo).

23. Vid. nota 6 y Millares Carlo: Don José de Eguiara y Eguren y su Bibliotheca Mexicana, Ediciones Filosofla y Letras, México, 1957.

24. Vid. nota 5 .
} 
Para la utilísima Biblioteca Enciclopédica Popular de la Secretaría de Educación Pública, de México, el conocedor feijoniano Agustín Millares Carlo seleccionó, prologó y anotó el volumen $\mathrm{XL}$, titulado Dos Discursos de Feijoo sobre América, que en mucho nos ha servido de pauta para las presentes notas. ${ }^{25}$

Por lo demás, la figura del maestro de Oviedo sigue alentando en el esclarecimiento de muchos puntos de la cultura mexicana. El año pasado, en un ensayo nuestro publicado en París, insistíamos en la saludable distinción de amor a la patria y pasión nacional, para entender ciertos problemas de España con los países hispanoamericanos. ${ }^{26} \mathrm{Y}$, cuanto más se ahonda en los intereses intelectuales del núcleo jesuita expulso, más se percibe la influencia bienhechora de Feijoo en el establecimiento de la filosofía moderna en México, con sus resultantes políticas y sociales.

El último estudio de Bernabé Navarro, publicado en marzo de 1964 como anticipación del libro Cultura Moderna en México en el siglo XVIII, reconoce la guía del maestro de Oviedo para tomar nuestro camino a la modernidad. ${ }^{27}$

Dice Jiménez Rueda que, al finalizar el virreinato, «la prosa tomaba por modelo al P. Benito Jerónimo Feijoo en su Teatro Crítico; al P. José de Isla en las Sátiras y a don José Cadalso en Los Eruditos a la violeta». ${ }^{28}$ Buena huella de esta aceptación debe ser el hecho de que casi no hay biblioteca en México que no posea tomos del Teatro o de las Cartas en sus ediciones del xviII.

En fin, para la historia y genealogía de la familia de los Feijoo en México, por ahora sólo podemos ofrecer el nombre de un personaje que en 1738 era Chantre de la metropolitana, el licenciado Sebastián Feixó y Centellas, como lo nombra la Gaceta de México. ${ }^{29}$

Tal es nuestra grata tarea de repaso para quien hizo severa crisis literaria para Sor Juana Inés de la Cruz, «la famosa monja de México».

\footnotetext{
25. Vid. nota 6 .

26. Cruz, Salvador: Estudio en el volumen Tres Ensayos sobre nuestra América, Biblioteca Cuadernos, Paris, 1963.

27. Vid. nota 14. El volumen apareció antes de finalizar 1964 (México, Imprenta Universitaria).

28. Jiménez Rueda, Julio: Historia de ta Literatura Mexicana, 7.8 ed., México, 1960.

29. Gaceta de México, núm. 133, diciembre de 1738.
} 
Tal es nuestra sencilla contribución al bicentenario de la muerte de Feijoo, el ensayista animoso; pues, como él mismo escribió, "el animoso que no recela dar las velas al viento, aunque prevea los peligros del golfo, logra, dando a luz los pensamientos que le sugiere su genio elevado, ser conocido y estimado de los hombres de inteligencia por Io que es».

Y España y América saben quién es Feijoo. 